SECCIÓN TEOLOGÍA 



\title{
El mal como posibilidad de la libertad y el poder según Hans Urs von Balthasar
}

\author{
JORGE VARGAS ABARCA \\ Instituto Profesional Catequístico UC (Chile) \\ jvargasb@uc.cl
}

\begin{abstract}
Resumen
Este estudio presenta cómo el mal ha ido configurando el actual dramatismo del hombre según el teólogo suizo H. U. von Balthasar. El punto de partida de este suceso es el rechazo de su condición originaria como ser singular que lo constituye a sí mismo y lo relaciona con el ser Absoluto, dejándolo a la deriva de su propia libertad y poderío. De modo que el mal se presenta como la posibilidad que tiene el hombre, en su deseo de autoreferirse en su singularidad, al desconocer el propio acontecimiento del ser que lo trasciende. Para ello, se darán a conocer los fundamentos que subyacen a la problemática del mal y su desarrollo en la historia, así como el acontecimiento de Cristo como el garante de esta nueva refiguración que desea establecer Dios con el hombre.
\end{abstract}

Palabras claves: ser, conciencia, mal, libertad, poder, teología de la liberación.

\section{The badly as possibility of freedom and power according to Hans Urs von Balthasar}

\begin{abstract}
This study presents like the evil has gone configuring the current drama of the man as the Swiss theologian H. U. von Balthasar. The point of split of this event is the refuse of his origin condition like being singular that constitutes it to himself same and relates it with the Absolute being, leaving it to it derives of his proper freedom and power. So that the evil present like the possibility that has the man, in his wish of auto-refer in his singularity, to the without knowing the proper event when being that the transcend. For this, will give to know the fundaments that subjacent to the problematic of the evil and his development in the history, like this as the event of Christ and the guarantee of this new refiguring that wishes to establish God with the man.
\end{abstract}

Key words: be, conscience, badly, freedom, power, theology of the release.

Licenciado en Teología, Pontifica Universidad Católica de Chile. Magíster en Ética Social y Desarrollo Humano, Universidad Jesuita Alberto Hurtado. Profesor del Instituto Profesional Catequístico UC (ex Hogar Catequístico). Entre sus publicaciones recientes destaca "El pensamiento social de Don Enrique Alvear: un ejercicio de desvelamiento a la luz de la tensión Doctrina Social de la Iglesia/Teología de la Liberación" (2007). 


\section{Introducción}

Esta investigación emprende la búsqueda sobre la cuestión del ser en el teólogo suizo Hans Urs von Balthasar (1905-1988), principalmente por medio del estudio de su trilogía: Gloria, Teodramática y Teológica y de la pregunta metódica que nos acompañará para develar tal misterio: ¿La singularidad del ser es negativa o se torna positiva en la medida en que se constituye don en el Espíritu Santo? Lo que hace posible articular ciertos postulados que están a la base del centro del drama para nuestro autor y que afectan la relación que se establece entre el ser singular concreto y el ser en general como manifestación del ser absoluto.

Particularmente, se abordará la experiencia del mal, que es desarrollada en el volumen IV de la Teodramática, dedicada a La Acción ${ }^{2}$. Y que, como se verá, no puede estar ajena a las nociones de libertad y poder. Ya que, tal como nos indica Balthasar: «Al menos en su propio ámbito histórico puede percibir el hombre la conexión entre libertad, poder y mal. El mal en el mundo procede, como bien sabe por propia experiencia, de la libertad, que para el mal se sirve del poder, del propio o del ajeno, un poder que está siempre ahí, y que en sí no es malo, pero que posee en su interior una tendencia al mal en el sentido de que representa un medio de dominio» ${ }^{3}$.

El método que seguiremos es analítico sistemático, por lo que intentaremos aproximarnos a una respuesta a partir de los propios textos balthasarianos. Lo haremos presentando una breve aproximación de su pensamiento, principalmente dentro de su trilogía. Además, se establecerá como punto de partida: la paradoja natural del hombre. Su rechazo, que ocasiona la posibilidad del mal. El problema mismo del mal. Una crítica a la Constitución pastoral Gaudium et Spes del Concilio Vaticano II y a la Teología de la liberación, que según Balthasar no han planteado con suficiente fuerza, lo negativo que impera en este mundo (el mal), ni la urgencia por el nuevo mundo que tendrá que venir con Cristo. Para

\footnotetext{
1 Se ha tomado la versión en español de esta gigantesca obra. Y en adelante se citará Gloria con la sigla GL, Teodramática con la sigla TD y Teológica con la sigla TL, especificando el volumen correspondiente y el número de página.

2 El esquema de la Teodramática es muy sencillo. Se comienza con un Prólogo para situar la cuestión del drama entre Dios y el hombre, I. Luego se presentan los personajes teológicos; Dios: Personaje principal. El hombre: y su papel en el drama, II. Cristo: personaje que media entre Dios y el hombre. María: fecundidad de la humanidad y de la Iglesia, III. Posteriormente se desarrolla la acción, en este escenario de dramaticidad a la largo de la historia, IV. Y finalmente el desenlace, V.
}

3 TD 4, 128. 
finalmente, desarrollar una aproximación a la cuestión del ser intentando responder a nuestra pregunta metódica.

\section{Aproximación al pensamiento del autor}

A mi juicio, Balthasar es un filósofo y teólogo completo y complejo a la vez, por la gran cantidad de autores que domina, desde la época clásica, pasando por la medieval, hasta la contemporánea, haciendo uso de sus aportes, aciertos y límites para dialogar con ellos, que se hace difícil distinguir que es lo propio y novedoso de aquellas lecturas que trae tanto implícita como explícitamente en sus textos y que exige del lector dominar también a dichos autores para poder comprender su reflexión. Además, es tan variada y abundante su producción, que incluye obras biográficas (de los Padres de la Iglesia, por ejemplo), escritos sobre espiritualidad, traducciones de diversos autores y su trilogía, que realizar una síntesis de su pensamiento es una empresa muy difícil. Por suerte para nosotros el propio Balthasar quiso contestar la siguiente pregunta motivado por muchas personas que le preguntaban: «ipor dónde hay que empezar para comprenderle a usted?». Así que tal como reza la máxima: «Homero se entiende con Homero», intentaremos presentar el propio pensamiento que Balthasar hace de sí mismo. Es decir, afirmando que «Balthasar se entiende con Balthasar». Ahora bien, nuestro propio autor plantea que este intento de resumen «corre el peligro de ser demasiado abstracto»... por lo que «debemos limitarnos a presentar un esquema de la trilogía: Estética, Dramática, Lógica» ${ }^{5}$. Y que por lo demás, es el campo de estudio de nuestro trabajo.

El teólogo suizo inicia su reflexión esclareciendo la situación que experimenta el propio hombre en su contingencia y finitud. En sus palabras, el hombre «existe como un ser limitado en un mundo limitado, pero su razón está abierta a lo ilimitado, a todo ser; la prueba consiste en el conocimiento de su finitud, de su contingencia: yo soy, pero podría no ser. Y muchas cosas que no existen podrían ser. Las esencias son limitadas mientras que el ser no lo es ${ }^{6}$. Esta escisión, la 'distinción real' de

4 H. U. vON Balthasar: "Intento de resumir mi pensamiento", Communio (E) IV (1988), 284.

5 Ibíd., 284.

$6 \quad$ Nótese según Santo Tomás la diferencia entre el ser por sí, que es Dios, y el ser en sí, que es la criatura: Ergo oportet quod omnis talis res cuius esse est aliud quam natura sua habeas esse ab alio. Et quia omne quod est pert aliud reducitur ad id quod est per se sicut ad causam primam, oportet quod sit aliqua res quae sit causa essendi omnibus rebus eo quod ipsa est esse tantum, T. DE AQUINO: El ser y la esencia, en Opúsculos y 
Santo Tomás, es la fuente de todo pensamiento religioso y filosófico de la humanidad» ${ }^{7}$.

De ahí que intente desarrollar la polaridad que se establece entre lo finito y lo infinito. Y que para él no es otra que la distinción real del ser en su misterio inefable de poseerlo todo y a la vez de carecer de todo, que nos da la clave para comprender al propio hombre y al misterio que lo sostiene en su ser ${ }^{8}$. Por tanto, es el hombre en su propia finitud que desea conocer y alcanzar lo que va más allá de sí mismo. Es por ello, que para Balthasar «La razón humana debe abrirse hacia lo infinito»? y

cuestiones selectas. Vol. I. BAC, Madrid, 2001, 30-77 (cita de la p.64). En palabras de Balthasar «Así el esse, como piensa Tomás, es totalmente pleno y totalmente vacío: pleno porque es lo más noble, el efecto primero y más peculiar de Dios, porque 'Dios con el ser produce todas las cosas', y 'el ser es anterior y más íntimo que todos los demás productos'; y vacío, porque no existe como tal, pues 'si no se puede decir que el correr corre, sino el corredor', 'tampoco se puede decir que el ser es’», GL 4, 362.

Ibíd., 285. Además plantea que, «Si él libremente crea el mundo y así comunica al mundo, al conferirle su no-necesidad gratuitamente, algo del estilo de su libertad, de su capacidad donante, libre y sosegada, y si esta libertad dadora no merece otro nombre que el de amor: ¿de qué otra 'materia' podría entonces 'ser' Dios, sino de 'amor'?», GL 5, 586. De otra manera, «El acto fundamental metafísico es el amor dentro de la diferencia del ser; el acto fundamental cristiano es el amor dentro de la diferencia Diosmundo: amor significa aquí siempre el acto total del hombre, que incluye en sí tanto la totalidad corpóreo-espiritual como, en particular, la razón percipiente», GL 5, 586-587.

8 Cfr. A. MEIs: El ser, plenitud atravesada por la nada, según Hans Urs von Balthasar. Ponencia presentada en el Congreso Internacional sobre la cuestión del ser en Hans Urs von Balthasar, 23 al 26 de septiembre de 2008, Pontificia Universidad Católica de Chile, especialmente ver la nota 4 . Es por ello que «Lejos de sobrevivir extrínsecamente a una especie completa, pensada como posible (que puede ser o no ser), la posibilidad de todo lo posible radica en la realidad: en que un ser puede ser introducido en la plenitud englobante del ser real y admitirlo en su comunión. Así, el esse es a la vez communissimun - aquello en que todas las cosas comulgan como en lo más perfecto que se pueda concebir- e intimum quod profundius omnibus inest, que funda, como se ha dicho, la más íntima unidad de cada ser singular y particular (...). No tiene subsistencia en sí mismo, sino que es inherente a las naturalezas: esse non est subsistens sed inbaerens», GL 4, 361. Además, para Balthasar, «Nada hay más rico y más pleno que el ser en su magnífico, absoluto e inefable triunfo sobre la nada (sin esta plétora el ser no es realmente pensable, vagaría como un duende sólo en principios impensados del pensamiento), pero sólo por una vez puede esta plenitud expandirse de manera absoluta: en Dios; pero, puesto que ella no tiene que afirmarse contra nada (dado que la nada es nada), no tiene tampoco necesidad, al sustentarse en sí, de encerrarse en una circunscripción esencial para después quizá, saliendo de ahí, comunicarse más allá de sus confines (que no tiene)», GL 5, 574.

$9 \quad$ H. U. VON BALThasar: "Intento de resumir mi pensamiento", Communio (E) IV (1988), 285. También «El hecho de que el ente sólo puede ser real mediante la participación en el acto de ser, remite a la antítesis integradora de que la plenitud del ser sólo llega a ser real en el ente singular; pero el hecho de que el ser (heideggeriano) 
«Nuestra filosofía será pues esencialmente una meta-antropología, al presuponer no solamente las ciencias cosmológicas sino también las antropológicas, superándolas hacia la cuestión del ser y de la esencia del hombre» 10 .

Si lo anterior es cierto, Balthasar recupera en dicha polaridad el nexo entre lo finito y lo infinito que se da de manera plena en el ser. Y para ello, debe valerse de una experiencia originaria común a todo ser singular concreto que le permita la apertura al ser en general y por ende al ser absoluto. En efecto, «El hombre no existe más que en el diálogo con su prójimo. El niño es evocado a la conciencia de sí mismo por el amor, por la sonrisa de la madre. El horizonte del Ser infinito se abre para él en este encuentro revelándose cuatro cosas: 1) que él es uno en el amor con su madre al tiempo que no es su madre; 2) que este amor es bueno y, por tanto, todo el Ser es bueno; 3) que este amor es verdadero y, por consiguiente, el Ser es verdadero; 4) que este amor provoca alegría y gozo, y por tanto todo Ser es bello» ${ }^{11}$. Para Balthasar, «Lo Uno, lo Bueno, lo Verdadero, lo Bello, es lo que llamamos atributos trascendentales del Ser porque sobrepasan todos los límites de las Esencias y son coexistentes al Ser. Si hay una distancia insuperable entre Dios y la criatura, si hay una analogía entre ellos que no puede resolverse en

puede explicarse sólo en la existencia (espíritu) comprende la dependencia del ser con respecto a lo existente y, de este modo, su no-subsistencia», GL 5, 578.

10 Ibíd., 286. También A. Meis desarrolla la idea de que el hombre, en cuanto ser material no es sólo persona, sino también individuo de su especie. Vid. A. MEIs: "La persona en cuanto singularidad concreta según Hans Urs von baltasar", Teología y Vida, $\mathrm{n}^{\circ} 42$ (2001), 440-467.

11 Ibíd., 286. Para un desarrollo más acabado sobre esta experiencia originaria, cfr. C. AVENATTI: La sonrisa femenina como configuradora de la subjetividad: el tú de la madre y el tú de Beatri\%: Ponencia presentada en el Congreso Internacional sobre la cuestión del ser en Hans Urs von Balthasar, 23 al 26 de septiembre de 2008, Pontificia Universidad Católica de Chile. Además, agrega Balthasar, «Y precisamente porque sabemos desde el principio que el tú de la madre no es el yo del niño, sino que ambos centros vibran dentro de la misma elipse de amor; porque conocemos también desde el principio que este amor es el bien supremo y absolutamente suficiente, más allá del cual no se puede esperar a priori nada más alto; porque en este yo-tú se encierra fundamentalmente (como en el paraíso) la plenitud de la realidad, y todo cuanto se puede experimentar más tarde, como desengaño, deficiencia y nostalgia ardiente es tan sólo derivación de aquel amor, precisamente por eso todo viene iluminado por el rayo de luz de este origen -yo y tú y mundo- con una irradiación tan clara y pura que incluye en sí una apertura a Dios», H. U. VON BALTHASAR: "El camino de acceso a la realidad de Dios", Mysterium Salutis, II. Cristiandad, Madrid, 1969, 29. 
ninguna forma de identidad, entonces tendrá que existir también una analogía de los atributos trascendentales en la criatura y en Dios» ${ }^{12}$.

Pero, da un paso más, no sólo esclareciendo que el ser singular concreto comparte una experiencia originaria que le permite aprehender el ser y que más tarde puede llegar a comprender, sino que es el propio ser quien le da la clave de su existir y misión en el mundo por medio de sus propios atributos. Con ello, no sólo intenta generar un discurso en torno al ser, de manera abstracta y lejana a nuestra realidad, sino que el ser es lo más concreto que puede existir en la realidad. En palabras del teólogo suizo: «En vista de ello yo he intentado construir una filosofía y una teología a partir de una analogía no ya del Ser abstracto, sino del Ser tal como se encuentra concretamente en sus atributos (no categoriales, sino trascendentales) (...) Y así se puede construir primero una estética teológica (Gloria): Dios aparece (...) ¿Cómo distinguir al verdadero y único Dios vivo de Israel de todos los ídolos que le rodean y de todos los intentos filosóficos y religiosos por alcanzar a Dios? Se puede continuar con una dramática: ¿Cómo afronta la libertad absoluta de Dios, en Jesucristo a la libertad relativa, aunque real del hombre? ¿Habrá quizá una lucha mortal entre las dos en la que cada una defenderá contra la otra lo que ella concibe y elige como lo Bueno? ¿Cuál será el desarrollo de la batalla y la victoria final? Y se puede terminar con una lógica (una teo-lógica): ¿Cómo llega Dios a hacerse comprender por el hombre? ¿Cómo puede una Palabra infinita imprimirse en una palabra finita sin perder su sentido? Es el problema de las dos naturalezas de Cristo. ¿Y cómo llega el espíritu limitado del hombre a captar el sentido ilimitado del Verbo de Dios? Este será el problema del Espíritu Santo» ${ }^{13}$.

Es por esta razón, por la propia autenticidad del ser que se da en todos los seres singulares que comparten el mismo ser trascendentalmente en el propio ser absoluto, que se hace necesario mostrar su legado y presencia en la historia (Estética), para poder aceptarlo o rechazarlo en su propia libertad y autoconciencia

12 Ibíd., 286. Balthasar nos aclara que, «En la primera experiencia radical de mí mismo puedo distinguir, pero no dividir, entre mi «modo de ser» (modus subsistentiae, tropos tes hyparxeos) y mi captación del ser como lo más general», TD 2, 193. «Pero habiendo concebido Tomás el esse como la no subsistente plenitud y perfección de toda realidad y como máxima 'semejanza de la divina bondad', Dios es alejado, de un modo nuevo y mucho más radical, más allá y por encima de todo ser del mundo, de toda calculabilidad y finalidad de las estructuras mundanas reales e ideales como 'lo totalmente otro' en toda su verdad y seriedad», GL 4, 354.

13 Ibíd., 287. Balthasar tiene claro que su trilogía no obedece a una secuencia trinitaria, sino más bien que ésta se desarrolla perijoréticamente. En palabras del teólogo suizo: «Parece presuponer que nuestro proyecto está organizado trinitariamente. Pero no es así; al contrario, en las tres partes se habla de la Trinidad de Dios», TL 1, 22. 
(Dramática), y finalmente poder comprenderlo (Lógica). Lo que hace Balthasar es construir un andamiaje para poder en definitiva adherir a Dios como aquello infinito que nos desborda y que nos sostiene en nuestra finitud, allí en el misterio del propio ser que se presenta como invitación en nuestra existencia. Por este motivo, el cristianismo es y sigue siendo — según Balthasar - quien mejor ha podido acercarse a este misterio inexorable. Para nuestro autor: «La respuesta cristiana está contenida en los dogmas fundamentales de la Trinidad y de la Encarnación (...) categóricamente rechazados por la razón humana que se erige como absoluto» ${ }^{14}$.

He ahí el riesgo al que se ve enfrentado el ser singular concreto en no reconocer esta distinción real, esta polaridad entre lo finito y lo infinito, que como diremos más adelante es por el rechazo a la paradoja natural del hombre lo que posibilita que el mal pueda acontecer producto de nuestra libertad y del poder que nos ha sido entregado al participar del ser.

\section{La paradoja natural del hombre}

Para entender la problemática del mal, Balthasar establece como punto de partida el reconocimiento de la paradoja natural del hombre, que ya ha sido presentada por Santo Tomás de Aquino y por Henri de Lubac $^{15}$. A saber, que el hombre para ser plenamente hombre necesita de sí mismo para desarrollarse, pero sabiendo que su existencia es dada por otro. Por ende, que para ser pleno requiere de este otro, que es Dios ${ }^{16}$. En este sentido, el ser singular concreto debe experimentar en primer lugar una apertura a su propio ser, que viene dada como posibilidad de su misma estructura creatural ${ }^{17}$. Para ello, la conciencia es la encargada de

\footnotetext{
$14 \quad$ Ibíd., 287.

15 Cfr. TD 4, 132. Balthasar presenta la paradoja tomista siguiendo a de Lubac: «el hombre aspira a completarse en un Absoluto que él, aún siendo causa sui, no puede llegar a alcanzar ni por sí mismo ni con la ayuda de un ser y un bien finito cualquiera», TD 2, 208.

16 Además explica, «Dios es absolutamente Otro sólo en cuanto non-aliud, no-otro (Cusano): como quien envuelve a todos los seres finitos bajo el único manto de su ser indivisible hasta que ellos — como seres que no son él sino que deben su posibilidad a su poder y su potencialidad (de aprehenderlo como realidad y de refugiarse junto a él) a su libertad ingeniosa y creadora- están en disposición de participar en una distancia infinita de su realidad», GL 5, 574.

17 Esta situación ya ha sido expuesta en TD 2: «Traigamos a la memoria un breve resumen de lo expuesto: la libertad finita, aunque no se le pueda negar un momento de absolutez, no es dueña de su propio fundamento y su propio ser, sólo puede
} 
manifestar el ser al propio ser singular ${ }^{18}$. Pero, siguiendo dicha paradoja humana: «Para ser ella misma está siempre apuntando a ese más allá, lo que en un primer momento se puede describir como la simple apertura del ser en general y, con ello, también a la verdad y al bien, todo lo cual está dado infaliblemente en el despertar de la conciencia a sí misma, en la reflexio completar ${ }^{19}$.

Dicha reflexión, le permite articular, en sentido más profundo, su ser singular en el ejercicio de su propia autoconciencia que se descubre como dada y que por tanto, le permite la captación del ser en general. Esto significa que el ser singular concreto se abre al ser en general en la medida que se interioriza de su $\operatorname{ser}^{20}$. Sin embargo Balthasar nos recuerda que: «En cuanto ser que debe su existencia, no puede la conciencia identificarse con el ser absoluto, sino sólo con una 'imagen' de este absoluto, al cual se siente necesariamente referida, en su propio 'de dónde' y 'hacia dónde' que le resultan incomprensibles» ${ }^{21}$. Este punto es importante, hay un deseo manifiesto de parte del ser singular de querer aprehenderse a sí mismo y por ende al ser en general en la reflexión que hace de sí, pero no hay una identificación con el ser absoluto. Dejando abierta la inquietud, para que al final de su propia existencia conozca al dador de su ser, teniendo que aprehender solo una «imagen» de él. Una

plenificarse más allá de sí misma», TD 4, 129. Por otra parte, se puede apreciar el aporte de Lafont en rescate del olvido del ente, «Dios se da a conocer y asimila al hombre a sí mismo mediante un proceso de presencia y de ocultamiento, de don y de prohibición, de alianza y de olvido, un juego que es en realidad una pedagogía de la comunión (...) Dios no ha descubierto todavía todo su misterio (...) Ese secreto es el que nos entrega Jesús por la cruz, pronunciando el nombre de Padre y siendo reconocido como Hijo», G. LAFOnT: Dieu, le temps et l'être. Cerf, Paris, 1986, 211ss.

18 Ahora Balthasar deja en claro que: «Este giro del razonamiento (la atribución del ser-finito- es atribución de un bien) sólo es posible como reflexión ulterior sobre el lado oscuro de la existencia humana. Para la conciencia que se está despertando, la infantil, la reflexión no es posible», TD 4, 130.

19 TD 4,129. Además nos señala que, «Esta experiencia implícita sólo es factible para una naturaleza que, en su núcleo subjetivo, sea espíritu, capaz, por tanto, de realizar aquello que el Aquinate llama reflexio completa: una aprehensión plena de sí mismo al ascender sobre sí para pasar a otro tú, conocido como otro y como amante», H. U. vON Balthasar: "El camino de acceso a la realidad de Dios", en Mysterium Salutis, II. Cristiandad, Madrid, 1969, 31.

20 Balthasar señala que, «La conciencia es primeramente un ser que se debe a otro, y que existe como apertura al ser y del hacer-ser de todo lo que en el ser aún es o puede ser», TD 4, 129.

${ }_{21}$ TD 4, 129. Además, «Se trata de un conocimiento incoativo en el que en cualquier caso se capta lo divino como lo absoluto, y por ello como lo que fundamenta todo lo mundano, como principium et finis (DS 3004), a la vez que como 'incomprensible' (DS 3001) a partir de lo mundano (Rm 1, 19 s.)», TD 4, 131. 
manifestación del ser absoluto, en el ser en general como son los trascendentales: Bien $^{22}$ y Verdad ${ }^{23}$.

Con ello llegamos al núcleo de la paradoja: «Este ser que-serelaciona-consigo-mismo es, gracias a esta determinación, libre: 'el yo es libertad'. Pero en su libre autoconciencia conoce el yo que toda esa relación no está puesta por sí mismo, sino 'gracias a otro', en el cual solamente puede alcanzar 'equilibrio y quietud', gracias a un 'yo infinito', o sea, Dios, en virtud del cual recibe su segunda determinación, la de un 'yo teológico'» ${ }^{24}$.

\section{Rechazo de la paradoja natural}

Para Balthasar el rechazo de la paradoja significa, a su vez, el rechazo de todos los bienes que se extraen a partir de ella. Aquí radica el eje articulador del actual escenario patético del mundo que, como veremos a continuación, relaciona inevitablemente libertad, poder y mal: «Toda forma por la que intenta el hombre prescindir de su radicación en Dios y obtener la fijeza en sí mismo, es una tentativa de adueñarse de sí mismo en su libertad, un asalto al poder. Y mientras aparezca Dios preferentemente en la figura de la omnipotencia, el yo cree encontrar en

\footnotetext{
22 «Esto se le vuelve particularmente nítido cuando reflexiona sobre el 'bien', pues el hecho de que se posee como autoconciencia, y no por sí mismo, sino de un modo tal que hace que se reconozca debido a otro, apunta a la bondad de su fundamento» TD 4, 129. Además, «Lo seguro es que la libertad finita (...) en la apertura de la luz del ser, desvela en sí otra indiferencia más profunda en la que puede dejar-ser en sí mismo a lo bueno, sea finito o infinito, a causa de su bondad, sin intentar aprehenderlo para sí», TD 2, 195. Para un análisis detallado se puede apreciar la aproximación del Aquinate sobre el bien en T. DE AQUiNo: El Bien, en Opúsculos y cuestiones selectas. Vol. I. BAC, Madrid, 2001, 339-394.

23 «La prioridad lógica de la paradoja natural (respecto a un 'existencial sobrenatural' en cuanto ya conocido siempre) explica finalmente que toda anticipación de la plenificación prevista por Dios es, a pesar de las apariencias, bybris, y tanto más cuanto más cerca parezca la plenificación», TD 4, 132. Además, señala que «la verdad, aletheia, es el estado de no oculto del ser en cuanto tal siempre está develado en tanto que en general, pueda salir del oculto aislamiento en la nada y en el misterio del decreto divino y ofrecerse en la existencia, en la cual es entregado, como esencia revelada, a la mirada del conocimiento», H. U. VON BALThasar: La esencia de la libertad. Sudamericana, Buenos Aires, 1955, 139.

24 TD 4, 135. Ya lo había mencionado antes, «Expliquemos ahora sólo la paradoja fundamental de que en la autopresencia se manifiestan juntos los dos momentos: la absoluta incomunicabilidad de mi yoidad y la ilimitada comunicabilidad del ser en cuanto tal (que no se 'agota' en la plenitud de todos los entes mundanos en que subsiste)», TD 2, 192.
} 
ello una disculpa y hasta un estimulo para establecerse a sí mismo (en cuanto ‘imagen' de Dios) frente a él igualmente como poder» ${ }^{25}$.

El ser singular concreto que se sabe libre, comprende que a partir de sí es posible su autoposesión ${ }^{26}$ y su propia autorrealización. Lo que implica que en su propia estructura fundamental se encuentra presente la posibilidad de autodeterminarse en sí mismo ${ }^{27}$. En palabras del teólogo suizo: «Precisamente en este momento parece natural la posibilidad de una separación de poder y bien, precisamente cuando el que elige se pone a sí mismo como criterio del bien, y por ello subordina el bien a su propio poder. Esta es la tentación de los orígenes: la autonomía de 'ser como Dios conociendo el bien y el mal' $(\mathrm{Gn} 3,5)\rangle^{28}$.

Balthasar, siguiendo a Burckhardt, señala que en sí el poder no es malo $^{29}$, ya que «es una de las tres potencias (junto a la religión y la cultura) que dominan la historia humana; las considera malas si se aíslan de las otras dos. En este aislamiento son no sólo malas, sino además absurdas, es decir, incapaces de instaurar sentido a la existencia; por consiguiente el poder debe siempre estar vinculado a valores morales, religiosos y culturales o mantenerse detrás de ellos» ${ }^{30}$. A su vez, esto que está a la base de un ser singular concreto, también es posible que lo

25 TD 4, 136. Recordemos que Balthasar plantea que, «El ser mismo 'no es la luz', pero da 'testimonio de la luz' al remitir continuamente en virtud de su no-subsistencia. Por eso, donde en la filosofía occidental el ser se instaura como horizonte del cosmos, es entendido él mismo como esfera de la luz (Aristóteles) o mejor, como 'primera emanación' de una luz del 'bien' que reina más allá del ser, como la autoirradiación absoluta», GL 5, 581.

26 Cfr. TD 4, 132ss.

27 «La autodeterminación (que le ha sido dada) es la máxima capacidad propia de un ser espiritual (y en esto tiene razón el estoicismo), pues no puede ser subyugada por ningún poder externo. Pero en la donación de libertad brilla la bondad de la libertad absoluta, pues da lo más precioso que tiene, y brilla igualmente la omnipotencia de esa misma libertad absoluta, porque tiene lo que da», TD 4, 138.

28 TD 4, 140.

29 Desde otra perspectiva el término poder, según Foucault, «se caracteriza por poner en juego relaciones entre individuos (o entre grupos). Ya que, los mecanismos de poder funcionan en la medida que ciertas personas ejercen poder sobre otras. Por lo tanto, (poder) designa relaciones entre partes, donde un conjunto de acciones inducen a otras y son consecutivas unas de otras», M. FOUCAULT: Discurso, poder y subjetividad. Ediciones El cielo por asalto, Buenos Aires, 1995, 176-177. Ahora bien, habrá que consignar que para Foucault el poder no existe como tal, sino más bien existiría cuando es puesto en acción. «Es una estructura total de acciones destinadas a actuar sobre otras posibles acciones: incita, induce, seduce, facilita o dificulta; en último extremo, coacciona o prohíbe absolutamente; y siempre es, sin embargo, una forma de actuar sobre un sujeto actuante o sujetos actuantes en virtud de su actuación o de su capacidad de acción. Un conjunto de acciones sobre otras acciones», ibíd., 181.

30 TD 4, 141. 
experimente la propia comunidad humana, que desde sus orígenes se ha intentado autogobernar en busca de un anhelado bien común: «Lo que vale respecto a una persona singular (acompañar el carácter absoluto que posee su libertad con alguna forma de ética altruista para de ese modo imitar la identidad divina de poder y bien, que es la única que otorga sentido al ser) puede decirse también de todo ejercicio del poder político: 'Hasta el Estado erigido sobre más claros crímenes se ve obligado con el tiempo a desarrollar algún tipo de derecho y de civilidad'» ${ }^{31}$. El riesgo de poner la medida del poder en el ser singular concreto, a imagen de la identidad divina, supone una valoración distinta del poder que se aleja inevitablemente del bien. Lo que trae como efecto que la comunidad humana tenga que encontrar los mecanismos necesarios para combatirlo: «El abuso, siempre posible, del poder a lo largo de los siglos ha intentado ser neutralizado por diversas 'ficciones' que se han ido sucediendo: 'control del poder' mediante las leyes (en Platón) (...) 'limitación de poder' (en Locke)... 'división de poderes' (en Mostesquieu) (...) 'equilibrio de poderes' (en John Rawls)»»

Lo que Balthasar quiere señalar, es que el poder es parte constitutiva del ser singular concreto que, a su vez, participa del poder del ser absoluto. El problema está en que mientras que en el ser absoluto hay una identidad entre poder y bien, en el ser singular el poder toma un nuevo rostro haciéndose un instrumento de dominación. Es por ello que «Un ejercicio personal del poder no debe ser excluido de la vida social, y

31 TD 4, 141. Esta es la postura clásica de Aristóteles. En efecto, para él la política no es pensada como un saber diferente de la ética, de manera que la fractura entre lo público y lo privado no está sugerida y mucho menos tematizada en su doctrina. Se pueden confrontar los siguientes pasajes en Ética a Nicómaco, traducción por Julián Marías y María Araujo. BAC, Madrid, 1964: I, 1, (1094a -1, 1094b11); II, (1103b 3-6); V, 10, (1134a 23-26); VIII (caps. 11-12 y 13) el último libro X, 10, (1181a 13ss) es presentado por Aristóteles mismo como una introducción a la ciencia política, precisamente con el objeto de «llevar a una buena culminación, en la medida de nuestras capacidades, la filosofía de las cosas humanas». Por otra parte, en la Politica, traducción por Julián Marías y María Araujo. BAC, Madrid, 1964, podemos observar un buen resumen de la eticidad de la política en II, 7, (1266b 28-31); III, 9, (1280a 311281a 2). «El fin de la comunidad política son las buenas acciones y no la convivencia». Además, IV, 10, (1295a 25ss); VII, 1, (1323a 14ss). Quien desarrolla esta idea es D. OBERndörfer: La Política como ciencia práctica. Trad. de Guido Soage Ramos. ETHOS, Madrid, 2000, 20ss.

32 TD 4, 143. Escribe Baker, «Maquiavelo, en la medida en que él es el padre de la ciencia política moderna entendida como una inducción científica a partir de la historia, es aún más eminentemente el autor del divorcio entre política y ética (...) Pero debemos recordar que tal distinción es ajena a Aristóteles», E. BARKER: The Political Trought of Plato and Aristotle. New Cork, Dover Publications, 1997, 241. La traducción es propia. 
funcionará del mejor modo posible si tanto en el que manda como en el que obedece se expresan en la misma medida los dos datos de la poderosidad humana (poder y bien o amor). Esta estructura del poder, que es propia del ser humano en cuanto personal y social y que nunca fue seriamente impugnada en las antiguas culturas, choca en el mundo moderno no sólo en el ámbito político, sino continuamente con la instauración de la hegemonía de la razón instrumental, que se orienta primariamente a poder disponer de la naturaleza y que en este sentido, al reducir la naturaleza a la mera facticidad, puede renunciar al polo personal de reconocerse-debido, al bien, con lo que se entiende y se ejerce como puro instrumento de podens ${ }^{33}$.

Balthasar ve claramente que la razón instrumental -término acuñado por K. O. Apel-, ha estado invadiendo a partir de la modernidad todas las esferas de relaciones que el ser singular puede desarrollar. Por tanto, la propia estructura humana del poder queda sumida bajo un poderío artificial que no es capaz de trascender su existencia. Para presentar el inicio de esta nueva relación cita a Heidegger ${ }^{34}:$ «él muestra que no puede sorprender que el aparente primado del conocimiento en Descartes y Kant se convierta en el aparente primado de la absoluta voluntad de poder en Nietzsche» ${ }^{35}$. En esta lógica argumentativa, el teólogo suizo intenta presentar que el rechazo a la paradoja natural del hombre no sólo ha hecho menos pleno al hombre, sino que lo ha dejado a la deriva de su propio poderío, al no tener otra referencia que la de sí mismo, en una autoconciencia meramente instrumental, alejándose de la más real y verdadera, que logre plenificarlo: «Nietzsche establece esta voluntad de poder como lo absoluto, con lo que quedan destituidos los 'valores supremos' ofrecidos por un ser que se entrega a sí mismo (destituidos porque ellos se habían desvalorizado epocalmente) y el poder se convierte en 'principio de una nueva escala de valores'. Voluntad de poder significa exactamente: 'Opción por sí mismo (...) en cuanto dominio más allá de sí mismo', por lo cual 'es la voluntad la poderosidad que se capacita para el poder', y de

\footnotetext{
33 TD 4, 144. Esta es la tesis de Meinecke, cuando señala que cuando una institución llega a una instancia política se requiere de la exclusión del bien. El Estado corrige la naturaleza humana quien se caracteriza por la corrupción insuperable y el Estado pretende solucionar esto. Cfr. F. MEINECKE: La idea de la razón de Estado en la edad moderna. Centro de estudios políticos y constitucionales, Madrid, 1997, 8ss.

34 Cfr. C. CASALE: Heidegger en la obra de Hans Urs von Balthasar. Ponencia presentada en el Congreso Internacional sobre la cuestión del ser en Hans Urs von Balthasar, 23 al 26 de septiembre de 2008, Pontificia Universidad Católica de Chile.

35 TD $4,145$.
} 
cara además a una poderosidad cada vez mayor (idea del superhombre)» ${ }^{36}$.

Frente a este panorama de desolación y de exterminio del propio hombre al actuar libremente, desplegando su hegemonía de poder para sí mismo y en contra de sí mismo, Balthasar encuentra un apoyo en Heidegger, quien desarrolla una filosofía del ser, ahí, precisamente donde la paradoja natural del hombre encuentra su cometido. En la capacidad que tiene el ser singular concreto, llamado a la existencia de reconocerse arrojado por el ser en general, al cual le debe su existencia: «Contra esta incapacidad de recibir, que es para Heidegger la marca de una época para lo que todo se ha convertido en 'factible', ha elaborado una filosofía en la que la 'esencia del hombre se determina a partir de la esencia (verbal) de la verdad del ser por el ser mismo', de modo que el hombre en la radicalidad de su estructura receptiva tendría que existir para la riqueza y la pobreza del ser como agradecimiento de que el ser (se dé)» ${ }^{37}$.

\section{El problema del mal}

Una vez establecido el punto de partida, que es la paradoja natural del hombre y su rechazo, «La tematización del mal resulta inevitable tras presentar la libertad y el poder; en el mal es donde se alcanza su última intensidad la dramaticidad de la existencia personal y social» ${ }^{38}$. Ahora bien, tal como señala Balthasar: «No resultará fácil, al tratar el fenómeno del mal dentro de la perspectiva del 'escenario patético del mundo' en su horizontalidad, llegar a resultados satisfactorios, ya que (como mostraremos) el mal se encubre por necesidad; por ello se desfigura y en consecuencia necesita una instancia absoluta para desvelar su verdadera esencia (...) El desvelamiento último lo aporta la Biblia, en perspectiva veterotestamentaria como teología de la alianza y desde el punto de vista neotestamentario como teología del hombre-Dios que 'quita' el pecado del mundo mostrándolo así en toda su maldad: como 'pecado'» ${ }^{39}$. Y sigue argumentando: «La posibilidad del mal procede de la polaridad de la

\footnotetext{
36 Ibíd.

37 TD 4, 146.

38 TD 4, 148. Balthasar ya ha venido preparando la cuestión, «Esta autoproducción de la libertad finita entraña un riesgo no menor, la libertad en su finitud puede producir, también en su rango (como finito) el mal, este dramatismo lo refleja Gregorio: 'Pues esta semejanza divina conlleva un riesgo: tiene el poder de crear algo que ni Dios mismo puede crear, a saber, el mal, que se hace realidad (ousiôthê) únicamente en nuestra voluntad'», TD 2, 205.

39 TD $4,148$.
} 
libertad humana, que ha sido entregada y que se sabe entregada, por lo que al aprehenderse así debe reconocerse debida-a (y con ello transcendida): en un acto único de elección. En virtud de esta elección el bien absoluto donante permanece en un nivel latente, mientras su dimensión de ser un regalo aparece en todo su brillo a la libertad finita» ${ }^{40}$.

Para Balthasar el mal es fruto de nuestra propia libertad y, por ende, de nuestra relación con la libertad infinita que abriga nuestro ser singular concreto: «Pero en el carácter originario y permanente de haber sido regalado no podría el donante ser pensado como ausente, sino más bien como alguien que, en un acto permanentemente presente (a la vez en su infinito poder y en su infinita bondad), transfiere al ser finito algo que le pertenece a él mismo desde siempre. Por todo ello cuando la libertad finita se atribuye a sí misma su ser regalado (lo que en realidad pertenece al absoluto y es inseparable de él), se despoja al absoluto de algo que le corresponde para atribuirlo a la libre disposición de la libertad finita» ${ }^{41}$.

El teólogo suizo hace una explicación detallada que brevemente resumimos: «Esto quiere decir tres cosas. En primer lugar, que el dinamismo que remite la libertad finita a la infinita se apropia sólo el aspecto del poder, pues la bondad del absoluto no puede ser encajada en la autonomía» ${ }^{42}$. «Lo segundo ya lo hemos rozado; la contradicción debe quedar escondida, pues se trata precisamente, para aquel que no quiere reconocerse como debido-a, de su identidad absoluta. En ésta están y actúan siempre a la vez los dos aspectos: el acto del encubrimiento y su resultado (estar velado y no ser ya visible). En la simultaneidad a ambos el mal es la mentira» ${ }^{43}$. «El tercer aspecto se infiere de lo dicho: como el poder asumido tiene que recurrir a la mentira para cubrirse, esta mentira

40 TD 4, 149. Además, nos señala que «una vez asentado que toda voluntad libre sólo puede aspirar a algo bajo el punto de vista del bien -y que por tanto, en la esfera del ser 'imagen (similitudo) de la bondad divina' (Ver q. 22, ac - ad 2) aspira implícitamente al bien absoluto que es Dios y que en esta operación no está determinada más que por sí misma y, por consiguiente, está indeterminada en la elección de los medios para alcanzar el bien-, Tomás llega ya al umbral de la segunda cuestión», TD 2, 207.

41 TD 4, 150. En otro pasaje había señalado que «La gracia no sólo debe ser libremente otorgada sino que también debe ser libremente aceptada, merced a un influjo de la gracia misma en el agraciado», TD 3, 41. También que, «El hombre puede libremente elegir cuál es la libertad que prefiere: la de un puro origen a partir de sí mismo, con lo que soporta no tener ni razón suficiente ni objetivo satisfactorio para esta libertad autogobernable y por ello tiene que conformarse con el disfrute de su autonomía; o la de la actitud de agradecimiento continuo por el propio ser dirigido a la libertad absoluta, la cual ya desde siempre ha abierto a la finita el espacio en el que pueda realizarse a sí misma: en Christoì), TD 3, 42.

42 TD $4,150$.

43 TD 4, 151. 
no puede suprimirse a sí misma. En cuanto poder arrogado no es nunca el propio, sino uno en el que por necesidad se revela la presencia del infinitamente poderoso y bueno. Al adueñarse la libertad finita de este poder realiza dos gestos: separa el poder del bien que la regala y se pone a sí misma contra el bien absoluto y así bajo su juicio» ${ }^{44}$.

Aquí llegamos al núcleo del teodrama en la explicación de Balthasar. La libertad finita que debía orientarse a la infinita para plenificarse queda sumida al modo contrario de la paradoja natural: «El que se 'libera' en una autonomía total queda aprisionado por la autonomía total (que es sólo Dios), de modo que no puede librarse de sus cadenas sino por un acto de Dios. Ya el carácter de mentira del pecado nos lo hace ver; interesaba a la libertad que no reconoce a Dios mantener esa mentira, aunque para ello actúa en contra de su verdadero ser (que incluye su transcendencia en su origen a partir de Dios y en su orientación a él), pues acaba subyugada por el poder que se le ha regalado para que la oriente a Dios, y finalmente se 'dobla sobre sí' (incurvatio in se ipsum lo llama Agustín)» 45 .

El ser singular concreto al querer alcanzar su autonomía, queda prisionero no de sí mismo, como comúnmente se podría pensar, sino de su propio fundamento que es quien le otorga su ser. Ahora bien, para Balthasar esto da paso a la revisión de la historia de la humanidad en esta relación originaria y permanente con Dios, al modo de una batalla, particularmente en la historia de Israel: «La metáfora de una batalla inexorable es simplemente recordada para poner en claro la situación dramática de la confrontación entre el siempre-más del poder y bondad de Dios y el siempre-más del mal que se encierra en su trinchera, dramatismo que se deja ver cuando la ira de Dios cae 'sobre toda impiedad e injusticia de los hombres' (Rm 1, 18)» ${ }^{46}$.

La manera de reconocer este alejamiento de Dios, se conoce en términos bíblicos como pecado. Tema que es ampliamente tratado por Balthasar: en el pueblo de Israel, en los paganos y en Jesucristo. Por lo que, «El pecado se muestra como un desgajamiento del poder divino (que es y exige el bien), para ejercer su propio poder como puro poder...» ${ }^{47}$. Ahora bien, para Balthasar: «El pecado original oscurece un poco más el ya ampliamente entenebrecido escenario patético del mundo» ${ }^{48}$.
TD 4, 152.
TD $4,152$.
TD 4, 153.
TD 4, 160ss.

48 TD $4,168$. 
Volvemos una vez más a la paradoja natural, el rechazo hace que el ser singular concreto no pueda por sí mismo remediar su actual situación de dramaticidad en el mundo: «El empuje natural hacia Dios (desiderium naturale) está debilitado por un querer-ser-para-sí de carácter negativo, por lo que se encuentra alejado del principio de redención y sólo podrá avanzar en la exigencia de autosuperación con la ayuda de la gracia» ${ }^{49}$. Para Balthasar, lo anterior no es inmediato. Ya que, la constatación que hace el ser singular concreto de sí mismo y su entorno, lo lleva a contemplar un escenario patético que muestra el dolor y el sufrimiento de sí mismo y de los demás seres: «El dolor del mundo hace más difícil que ninguna otra cosa el acceso a Dios, que acaso sea justo (o hasta amoroso) para sí mismo, pero que no es capaz de hacerlo creíble en la tierra mediante su intervención. ¿Qué puede hacer el hombre en esta oscuridad? $\rangle^{50}$.

Por lo que para el teólogo suizo la alternativa es sólo una: «Si el hombre no quiere caer en la intrínseca contradicción de la rebelión, no puede esperar más que la respuesta propia de Dios. Y Dios no da otra que la locura de la cruz, la única que supera la 'locura' del dolor del mundo $»^{51}$. Entramos en un área tremendamente aguda. Ya que el ser singular concreto que ha querido mediante su propia libertad tomar el poder posibilitando el mal, no puede incluso por sí mismo salir de la esclavitud en la que se encuentra, al proclamarse como un ser autónomo. Tiene que ser el mismo quien le obsequia el ser, quien le otorgue nuevamente la capacidad que lo haga pleno, y que le permita trascender más allá de sí mismo, pero desde sí mismo hacia el ser real de su existencia para dar cabida a la paradoja natural que lo constituye.

En este sentido, es que se produce el encuentro entre el ser singular concreto y el ser absoluto en un único ser que asume la condición humana en su existencia para redimirla. Es aquí donde el hombre-Dios entra en la escena como el verdadero protagonista de la dramaticidad ${ }^{52}$ : «El Hijo de Dios no ha venido para quitar el sufrimiento, sino más bien para sufrir con nosotros, no ha venido para suprimir la cruz, sino para

\footnotetext{
49 TD $4,174$.

50 TD $4,178$.

51 TD 4, 178. Balthasar plantea que, «A partir de la cruz en cuanto amor absoluto (cargar con el pecado del mundo) toda la ética del amor propia del evangelio prepascual puede recibir un nuevo desarrollo: que los cristianos lleven y soporten los unos las cargas de los otros, el servicio a los hermanos al que Jesús dio tanto relieve; todos los frutos del Espíritu (Gál 5) y los diversos aspectos del ágape (1 Cor 13) pueden ser leídos desde ahí», TD 3, 124.

52 «Con la aparición de Cristo, al hombre le ha afectado algo que aún continúa, nunca podrá ser el mismo que era antes de Cristo», TD 3, 235.
} 
extender sus brazos en ella. De todas las especiales prerrogativas de la humanidad ésta es la única que Dios ha buscado para sí» ${ }^{53}$.

Esto quiere decir que en Cristo nuevamente el poder y el bien se identifican. Pero, el poderío de Cristo no es de este mundo, aunque ya vino para superar al primer Adán, ahora como el segundo: «Esto no impide que el Logos rechazado por el mundo haya creado el mundo, que el Adán psíquico haya sido hecho con vistas al segundo Adán, que es el celeste, y que por fin, el Logos, viniendo del mundo, 'venga a lo suyo'. Es lo suyo en cuanto viene de él y es para él, y es lo extraño a pesar de todo, en la medida en que no es lo pneumático lo que está en primer lugar, sino lo psíquico y sólo entonces lo pneumático» ${ }^{54}$. De ahí que Cristo siga siendo el modelo de acción para todo cristiano en la escena dramática que el mundo le ofrece al encarnar en él la perfecta paradoja humana: «Es preciso reconocer en Jesucristo y presentar como modelo al cristiano, la unidad de las dos cosas: la libre y la perfecta autodeterminación de la acción y de la actitud personal, por una parte, y por otra, la ordenación perfecta a la absoluta libertad divina que, para Jesús, es la voluntad del Padre, mediada por el Espíritu Santo. Este Espíritu no le dicta al pie de la letra la voluntad del Padre, sino que se la presenta y, en cuanto Espíritu propio del Hijo, actúa también en su libertad humana, para que ésta, en una decisión propia, se abra a la voluntad absolutas ${ }^{5}$.

Cristo ha abierto el espacio escénico para el hombre ${ }^{56}$, Balthasar nos dirá que «En el hombre ha quedado depositado un fermento que procede de lo absoluto, que por ello quebró la vinculación de la humanidad a la naturaleza cósmica y le otorgó una libertad, y con ello un elemento de absolutez que sigue conservando por don de Cristo, aun cuando se desgaje de su origen ${ }^{57}$. Para el teólogo suizo el ser singular concreto, si no reconoce su paradoja natural, estará siempre librando una batalla que, aunque por su aparente autonomía le brinde poder, jamás logrará alcanzar su verdadera plenitud de sentido. Es por ello que: «El primer Adán, de por sí, no es capaz de llegar a la plenitud; lo que tiene

\footnotetext{
53 TD $4,179$.

54 TD $4,445$.

55 TD 4,448

$56 \mathrm{Al}$ respecto Balthasar es claro en afirmar que dicho espacio ha quedado abierto en virtud de los méritos del misterio pascual realizado en Jesucristo, por eso en otro pasaje nos dice: «'La apertura del espacio escénico’: tal espacio quedó abierto en virtud de la predicación del reino futuro, se transfirió eficazmente a nosotros por la cruz y la resurrección y quedó dispuesto como ámbito de la acción a desarrollar entre Dios y el hombre», TD 3, 123.

57 TD 3,31 .
} 
que hacer es morir a sí mismo para ser elevado e integrado en el segundo. El que esto sea posible se lo debe al segundo Adán que, siendo su fin, es también su principio. Por eso posee Jesús, frente al mundo, esta libertad peculiar de actuar en él, pero no para perfeccionarle en su vertiente intramundana, sino para poner en él los signos del Reino que trasciende este mundo $»^{58}$.

Esto es importante en Balthasar se puede deducir que lo intramundano no es lo definitivo, sino lo que está más allá de este mundo. Ahora bien, aunque se reconoce que Cristo vino al mundo para liberarlo de la esclavitud del pecado, vino sobre todo para despertar el apetito de otro mundo mucho más perfecto y glorioso ${ }^{59}$ : «En el cielo nuevo y la nueva tierra no volverá a comenzar el mundo desde el inicio, sino que la creación de Dios recibe una transfiguración en la vida de éste, las obras del hombre 'le siguen' y determinan la forma de su bienaventuranza ${ }^{60}$. «En cierto sentido el drama de la salvación del mundo creado es efectivamente un preludio de la acción verdadera, pues los hijos de Dios redimidos y conducidos a Dios y a sí mismos encuentran su valor en ese mundo de Dios» ${ }^{61}$.

\section{La actual situación del mundo (una crítica a la Gaudium et spes y a la Teología de la liberación)}

Lo que ha hecho anteriormente Balthasar es una fundamentación de la apertura y del rechazo de la paradoja natural del hombre y sus consecuencias en la historia humana, pero se pregunta hasta qué punto el ser singular concreto está deseoso de reconocer esta paradoja: «El hombre regenerado en Cristo participa análogamente en la libertad de Cristo: liberado para una responsabilidad a realizar ante Dios y el mundo, posee el Espíritu Santo que le confiere una total disponibilidad en el marco de la absoluta libertad divina $»^{62}$. «Y todo esto en la paradoja de que, en cuanto 'criatura nueva', debe continuar viviendo en medio de las limitaciones de la antigua, hasta que la 'esperanza' llegue a transformarse en la visión de la 'cosa misma': 'Si Cristo habita en vosotros, aunque el

\footnotetext{
$58 \quad$ TD $4,448$.

59 Nótese la similitud con la que Benedicto XVI plantea en el tenor de toda su encíclica Spe Salvi que el cristiano debe apuntar más a los bienes sustanciales, que no son los de este mundo, sino los del definitivo.

60 TD 4, 182.

61 TD 4, 183.

62 TD $4,448$.
} 
cuerpo haya muerto ya a causa del pecado, el espíritu es vida a causa de la justicia' $(\operatorname{Rm} 8,10) »{ }^{63}$.

Bajo este contexto el teólogo suizo se plantea «La cuestión crucial de saber hasta qué punto es posible lanzar sobre este mundo esencialmente cerrado, las semillas de una vida abierta hacia Él y que viene de Él, de hacer brotar en lo que está 'muerto', es decir, sujeto a la corrupción en todas sus dimensiones, gérmenes de inmortalidad. Cómo implantar en el que no conoce ni busca más que una libertad de pura autonomía (sea individual o social) una libertad completamente distinta, donada por Dios y vuelta hacia él. Semejante obra de implantación no puede ser imposible, porque Cristo, ciertamente rechazado por el mundo, pero resucitado en su cuerpo, no se ha contentado sólo con predecir a los suyos el odio del mundo (Jn 15, 19) y de ponerles en guardia frente a los hombres (Mt 10, 17), sino que les ha enviado a todo el mundo para anunciar su mensaje (Mt 10, 28, 19), como ovejas en medio de lobos (Mt 10, 16), puesto que a él, el nuevo Adán, se le ha conferido todo poder no sólo en el cielo, sino también en la tierra, en la antigua tierra obstinada en su negativa $\left(\right.$ Mt 28, 18)» ${ }^{64}$.

El tema para Balthasar es la tensión que se manifiesta entre el mundo terrenal y el celestial. ¿Cómo operar en la lógica de este mundo y en su transformación al definitivo?: «puede existir algo así como el equivalente de una plenitud de sentido en el plano intramundano, y una eficacia de lo que podría llamarse 'política de los corderos', en la línea, por ejemplo, de una 'política de la no-violencia'? 'Gaudium et Spes, Luctus et Angor' ha hecho frente a la paradoja y ha tratado de decir lo que de positivo se podría decir a este respecto, pero, obligado es decirlo, haciendo caso omiso de la ley de la escalada del 'no' contra la del sí que describe el Apocalipsis» ${ }^{65}$. Sin duda que Cristo sigue siendo el referente y el camino que nos conduce a la plenitud definitiva de la humanidad. La propia Constitución marca su centralidad en este conocido pasaje citado por Balthasar: «Apelando a lo humano en el hombre, la Constitución pastoral ha hablado mucho de este humanum, que podría ser vere, plene (11,

\footnotetext{
63 TD 4, 449. De un modo similar Congar plantea que «Así la Iglesia (de la tierra) sigue totalmente esta lógica de la encarnación: sensible y humana de un cabo a otro y divina de un cabo a otro, teándrica como Cristo (...) la bendición de Dios no se recibe ya por pertenecer a un pueblo; si no se forma parte de su pueblo perteneciendo a Cristo por la fe y el bautismo (...) La unidad (espiritual) de los hombres en Cristo debe ser, pues visible, sensible y social, debe verse, puesto que la Iglesia es como una teofanía o una Cristofanía en forma colectiva y social...», Y. CONGAR: Los cristianos desunidos. Verbo Divino, Estella, 1967, 117-119; ver Chrétiens désunis. Cerf, París, 1937, 86ss.

64 TD 4, 449.

65 TD 4, 450.
} 
1), summe $(11,3)$, rationabiliter $(63,3)$ humano, si tomara la medida de toda la humanidad a partir del hombre-Dios: nonnisi in mysterio Verbi incarnati mysterium hominis vere clarescit, porque el primer Adán era la figura del segundo, el cual 'manifiesta plenamente el hombre al mismo hombre y le descubre su vocación superior' por la revelación del misterio de Dios $(22,1) »^{66}$.

No obstante, al mirar la Constitución pastoral critica el panorama que presenta del mundo. Ya que en su diagnóstico no consigue trascender la realidad a la verdadera realidad que está más allá de este mundo. Balthasar señala que la GS se centra en el aspecto positivo que tiene la Iglesia con respecto al mundo y su desarrollo, sobre todo en el progreso técnico ${ }^{67}$. Pero, no ve con la misma justeza su negatividad. Dejando la ambigüedad de pensar sólo en la convergencia del desarrollo del mundo con el desarrollo de la Iglesia. Y no denunciando su abandono a la dimensión trascendente y definitiva de la humanidad ${ }^{68}$. «Es aquí donde comienzan las aporías de la Constitución, en parte conocidas y en parte no. Conocida es claramente la tendencia hacia la unidad entre los hombres que favorece la tecnificación de la tierra (54), pero también sus riesgos: pérdida del sentido de la tradición, disgregación en disciplinas particulares, especialización excesiva y pérdida de la cultura general, creciente tensión entre la cultura de masas y la auténtica formación de élites, entre un 'humanismo meramente terrestre, o incluso contrario a la religión' y la verdadera transcendencia $(56 ; 61,1)$. A pesar de todo - y aquí lo desconocido y no dominado- se presenta como único ideal a conseguir la convergencia entre esta futura cultura global (universalis cultura, 61, 3) y la catolicidad de la misión de la Iglesia $(58,2) »^{69}$.

66 TD 4, 450.

67 Es la misma crítica que hace Benedicto XVI, en Spe Salvi, sobre todo en los números, 16 al 23.

68 El Romano Pontífice en su última encíclica no habla explícitamente de la transformación de este mundo, ni de lo que debemos hacer en él para alcanzar el definitivo, más bien apuesta a que esta esperanza que se traduce en la experiencia salvadora de Dios en medio de los hombres a lo largo de la historia sea un fermento en la masa por medio del testimonio. En sus palabras, «antes del encuentro con Cristo, los Efesios estaban sin esperanza, porque estaban en el mundo 'sin Dios'. Llegar a conocer al Dios verdadero, eso es lo que significa recibir esperanza», BENEDICTO XVI: Spe Salvi, 3. Nótese la similitud de este pasaje con este otro de H. U. von Balthasar: «Para el poeta como para el exégeta, la esperanza es el elemento dinámico de la existencia cristiana, ella es un elemento propiamente cristiano, que no poseen los paganos (1Ts 4, 13) puesto que ellos viven en el mundo 'sin esperanza y sin Dios' (Ef 2, 12)», H. U. VON BALTHASAR: "La esperanza entre la fe y la caridad", Communio, Vol. 3 (1996), 5-16.

69 TD 4, 451. 
Para Balthasar el que la Constitución no advierta la tensión en la que se encuentra el ser singular concreto, tanto a nivel político como social, es una clara vacuidad del drama que significa no reconocer su paradoja natural también en esos ámbitos; ni afirmando las consecuencias negativas que ha producido la historia de la humanidad en su poderío, ni su meta que va más allá de este mundo: «La Constitución advierte claramente que el individuo, en virtud de su contradicción interna, ha de librar 'una dura batalla contra el poder de las tinieblas que durará hasta el último día' $(37,2)$. Pero, cuando se habla de la convergencia entre la cultura universal y la pretensión de la Iglesia a la catolicidad, no se dice nada del combate que ha de desarrollarse igualmente en el plano de la sociedad, de la cultura y de la política, combate que con seguridad ha de ser más duro, porque las estructuras sociales inmanentes al mundo, en cuanto tales, no llegan a trascender la perspectiva de este mundo» ${ }^{70}$.

De ahí entonces, que también critique a los postulados al interior de la Iglesia que pretenden transformar este mundo, y cuya insistencia ha sido la emergencia de intentar dar solución a las injusticias sufridas por los cristianos más débiles. En palabras de Balthasar: «Desde aquí, cabe lanzar una mirada a la así llamada teología de la liberación y hacer ver su urgencia y su compleja naturaleza. Su mayor riesgo radica en querer encerrar en un sistema controlable la relación entre los dos Adanes y entre la acción terrestre y la del Reino de Dios, y así corre el peligro de caer en una nueva especie de racionalismo teológico. Su apelación a la primacía de la praxis no cambia nada en todo este asunto» ${ }^{71}$. Para entender estas críticas debemos mirar de modo muy sintético el florecimiento de la Teología de la Liberación. En efecto, a finales de los años sesenta, en América Latina se empieza a tomar conciencia de la

\footnotetext{
70 TD 4, 452. Una visión distinta es la que ofrece Juan Alfaro: «El cristiano espera la salvación no solamente para sí mismo, sino también para la comunidad humana y para la obra del hombre en el mundo, la historia (...) La esperanza cristiana no es auténtica sino tiene dimensión universal; en lo más profundo de sí misma incluye la autodonación del hombre al Dios amor y el amor a Dios es inseparable del amor a los hombres (1 Jn 4, 7-12.20-22). La caridad, plenitud de la esperanza, exige del cristiano esperar para los demás como para sí mismo, es decir, amor al prójimo como a sí mismo», J. AlFaro: "Las esperanzas intramundanas y la esperanza cristiana", Concilium (1970), 361. Desde otra perspectiva se puede observar la propuesta de personeidad y ser en J. ZiZIOULAS: El ser eclesial: persona, comunión, iglesia. Sígueme, Salamanca, 2003. Además, en esta línea por ejemplo encontramos a todas las vertientes de la Teología de la Liberación y al propio Alfaro citado anteriormente. También Metz plantea que a lo largo de la historia de la teología han habido tres paradigmas: el neoescolástico, el trascendental-idealista y el postidealista, siendo este último, donde él plantea su teología política. Ver J. B. MeTZ: Dios y Tiempo. Nueva Teología politica. Trotta, Buenos Aires, 2002, 120-121. 71 TD $4,453$.
} 
situación socioeconómica que experimentaban amplios sectores de la población y que permitían observar las grandes diferencias que existían entre los más ricos y los más pobres de nuestro continente ${ }^{72}$. Conjuntamente con ello, recordemos que empiezan con fuerza a surgir movimientos populares de liberación, en el cuál los cristianos también quisieron hacerse parte de ellos para remediar en algo las consecuencias y causas de estos males. Y las Conferencias Generales del Episcopado Latinoamericano, Medellín (1968) y Puebla (1979) habían denunciado tales atropellos, destacando con ello la injusticia y la pobreza que experimentaban sobre todo los más necesitados ${ }^{73}$. En este contexto, surge la denominada Teología de la Liberación ${ }^{74}$, como expresión de una reflexión teológica que asume su propia realidad histórica y que intenta reformular las verdades de la fe y proponer una nueva praxis cristiana, desde una nueva lectura del Evangelio, que es la de los pobres ${ }^{75}$. Por lo tanto, es la propia fe que intenta ponerse en práctica, para así poder transformar la realidad en la que se encuentra inmersa. El propio Gutiérrez define la Teología de Liberación como aquella «reflexión crítica de la praxis histórica a la luz de la palabra» ${ }^{76}$. En efecto, esta nueva realidad es la de los pobres y tal como lo expresa Jon Sobrino, «los pobres son el Sitzs im leben de esta teología» ${ }^{77}$. Por lo tanto, la temática central no gira primeramente entorno a una reflexión de la fe, sino a establecer el escándalo del hombre oprimido y deshumanizado, y a despertar la conciencia crítica del creyente frente a las innumerables situaciones de injusticia. El problema que ocasionó esta nueva manera de

72 Para un detalle mayor sobre su caracterización, corrientes y etapas ver J. C. SCANnONE: Teología de la Liberación y Doctrina Social de la Iglesia. Cristiandad, Madrid, 1987, 21-80. J. B. LiBAnIO: Teología de la Liberación. Guía didáctica para su estudio. Sal Terrae, Santander, 1989.

73 Cfr. Medellin, Pobreza 1 y 2; Puebla, 28-30.

74 Sin duda que la relectura del Concilio Vaticano II y el surgir de algunas obras como: Teología de la Liberación de Gustavo Gutiérrez, Opresión y Liberación de Hugo Assman, Jesucristo Liberador de Leonardo Boff, Liberación de la Teología de Juan Luis Segundo, entre otras, motivan la reflexión y sientan las bases de esta nueva forma de hacer teología.

75 Juan Luis Segundo prefiere hablar de pluralidad de Teologías de la Liberación, señalando que pese a nacer en Latinoamérica no es la única en esta clave, sino que existen otras como las minorías étnicas en EEUU, y otras expresiones en África, Sudáfrica y Asia, que sumados a posturas feministas y ambientales dan origen a un cuerpo mayor que comparten teólogos del Tercer Mundo. Citado por J. J. TAMAYO: "Teologías de la Liberación", en C. Floristán y J. J. Tamayo (eds), Conceptos fundamentales del cristianismo, Editorial Trotta, Madrid, 1993, 1364-1365.

76 G. Gutiérrez: Teología de la Liberación. Perspectivas. Sígueme, Salamanca, 14 ed., 1990, 136.

77 J. J. TAMaYo: “Teologías de la Liberación”, 1366. 
hacer teología, es el método escogido por ella para interpretar la realidad. Ya que, el elemento hermenéutico es el análisis marxista, que por medio de sus postulados sobre el materialismo histórico, concibe la realidad como la lucha de clases entre los ricos y los pobres, y por lo tanto, se apela a la igualdad de clases liberando al pobre de su esclavitud.

Se postula por tanto, que la salvación del hombre no puede darse sin una liberación económica, política y social que le permitan recuperar su real dignidad. Es por ello que la lucha contra la pobreza, la injusticia, la falta de educación y oportunidades son elementos constituyentes de la fe de un creyente y no tan sólo el resultado histórico de una opresión de unos sobre otros. Lo que acarrea como consecuencia que la «teología es comprendida como acto segundo, siendo el acto primero la praxis de la liberación, ante todo la de los cristianos, en un contexto histórico de injusticia y opresión ${ }^{78}$.

Habrá que añadir que hay dos Instrucciones emanadas por la Congregación para la Doctrina de la fe, firmadas por el Cardenal Joseph Ratzinger (actual pontífice) y aprobadas por Juan Pablo II que reflexionan acerca de esta nueva teología. La primera de 1984, Libertatis Nuntius es una explícita crítica a algunos postulados de la Teología de la Liberación $^{79}$ y la segunda de 1986, Libertartis Conscientia intenta salvaguardar lo positivo a partir de las propias temáticas que alude. De hecho, la primera Instrucción prepara el camino de la siguiente, por lo cual ambas hay que leerlas como un todo.

Además, se presenta a la Doctrina Social de la Iglesia como la auténtica praxis de liberación cristiana, ya que «La Iglesia, experta en humanidad, ofrece en su doctrina social un conjunto de principios de reflexión, de criterios de juicio y de directrices de acción para que los cambios en profundidad que exigen las situaciones de miseria y de injusticia sean llevados a cabo, de una manera tal que sirva al verdadero bien de los hombres» ${ }^{80}$. Por lo que hay una invitación explicita de la Iglesia a caminar y dialogar de la mano con la Teología de Liberación, ya que ambas se pueden nutrir y enriquecer mutuamente. Pues bien, bajo esa panorámica podemos entender mejor la crítica que realiza Balthasar a la teología de la liberación: «Ahora bien, puesto que esta llamada dirigida a los cristianos y a su decisiva responsabilidad en la transformación de la marcha de este mundo constituye un postulado esencial de su misión,

\footnotetext{
78 J. C. SCANnONE: Teología de la Liberación y Doctrina Social de la Iglesia, 26.

79 Un estudio en contra de la crítica lo aporta J. L. SEGUNDO: “Críticas y Autocríticas de la Teología de la Liberación”, en J. Comblin, J. I. Gónzalez Fauz y J. Sobrino (eds.), Cambio social y pensamiento cristiano en América latina. Editorial Trotta, Madrid, 1993, 215236.

80 Libertatis Conscientia, 72.
} 
dicha llamada pone de manifiesto, como nunca quizás hasta ahora, la situación dramática del cristiano en este mundo» ${ }^{81}$. Lo cual se constata en estos cuatro puntos:

1. «Desde el Génesis está llamado el hombre a modelar la tierra a su imagen, sabiendo que él mismo es imagen de Dios (...) Pero ¿qué ocurre cuando la organización del trabajo humano se pone al servicio de un aumento incesante del poder, no de los trabajadores ciertamente, sino de los que recogen los frutos de los trabajos de éstos? (...) en el mejor de los casos, puede conseguirse un equilibrio (lábil) y conservarlo (durante un cierto tiempo), no entre los dos polos opuestos de una miseria insoportable y de un lujo insensato o de una voluntad titánica de poder, sino entre una pobreza tolerable y un confort organizado para todos. Este esfuerzo cristiano por ayudar a cada uno a llevar una existencia conforme a los derechos humanos y a la dignidad de la persona, será tanto más ambiguo tanto más se vaya acercando a su fin. La razón es que los bienes culturales hoy disponibles que se ofrecen a los pobres y a los que ellos mismos aspiran, provienen de aquella parte del mundo en donde la técnica engendra la dinámica del siempre más (...) De ahí que la liberación cristiana tenga que estar preparada para el fracaso, a pesar de todo el esfuerzo terrestre» ${ }^{82}$.

2. «La no-violencia, proclamada como programa por Cristo en el sermón de la montaña, ¿debe tener sólo vigencia en la esfera privada e interpersonal y no también en la escena social y política? (...) El cristiano dentro del espíritu del sermón de la montaña, podrá intentar actuar y también procurar estimular a las masas, quizá sin un excesivo temor, a traspasar la frontera que les lleva a la táctica política. Pero, para fijar esa frontera tendrá que tener muy en cuenta lo que son realmente las relaciones de poder en este mundo ${ }^{83}$. Para

81 TD $4,454$.

82 TD 4, 454-455.

83 Esta es la tesis de M. Weber: «También los cristianos primitivos sabían muy exactamente que el mundo está regido por los demonios y que quien se mete en la política, es decir, quien accede a utilizar como medios el poder y la violencia, ha sellado un pacto con el diablo, de tal modo que ya no es cierto que en su actividad lo bueno sólo produzca el bien y lo malo el mal, sino que frecuentemente sucede lo contrario». Ahora al final plantea que «la política consiste en una dura y prolongada penetración a 
sí mismo podrá elegir el camino del martirio en pro de la justicia de Cristo, pero es muy cuestionable que pueda imponer esta lección a una gran masa de cara a lograr fines políticos e incluso humanos» ${ }^{84}$.

3. «La estrategia de la cruz no tenía lugar más que en la muerte, en la frontera misma del paso del Reino del más allá. No es posible actualizarla tal cual, como si fuera la única válida en medio de las lides terrenas de poder. Además no tenemos un solo ejemplo de la vida de Jesús, en donde hubiera peleado por su causa con medios terrestres de poder (...) Y ¿no son ciertas tácticas de no-violencia (aunque paradójicamente) manifestaciones de poder, una manera de imponer por medios inhabituales a los aparentemente más poderosos a hacer lo que no quieren? $\rangle^{85}$.

4. «La lucha por la justicia en pro de los pobres y de los oprimidos es un estricto deber cristiano, una obra de misericordia espiritual y corporal, según la cual el cristiano, e incluso cualquier hombre en este mundo, será juzgado (...) sin embargo esta lucha no puede ser más que un momento entre otros en medio de una lucha más amplia, es decir, en medio de la auténtica batalla del Logos» ${ }^{86}$.

Es por ello que el teólogo suizo plantea que «El verdadero bien (Lc $16,11)$ es mucho más que la libertad política o económica, que en el complejo de la política y más aún de la economía mundial, jamás podrá ser más que una libertad relativa. La 'auténtica libertad' es la que garantiza Dios mediante el don del Espíritu, aquella de la que un pobre y un oprimido pueden participar y llegar a vivir conscientemente, al igual que un preso en un campo de concentración o en un gulag» ${ }^{87}$.

Es por ello que para Balthasar está claro que «Esta zona suprema de la teología de la liberación es la prueba, por otra parte, de que las etapas

través de tenaces resistencias (...) sólo quien está seguro de no quebrarse (...) de responder con un sin embargo; sólo un hombre de esta forma construido tiene vocación para la política», M. WeBER: El político y el científico. Alianza, Madrid, 1996, 169 y 179. También N. LuHmann en Políticos, honestidad y alta moralidad de la politica, realiza un ejercicio semejante, pero no da soluciones, más bien abre la problemática.

84 TD $4,456$.

85 TD $4,457$.

86 TD 4, 457.

87 TD $4,458$. 
precedentes (de la lucha en pro de la justicia), a pesar de toda su urgencia, han de ser consideradas en su relatividad, al menos allí donde la liberación política y económica se halla en un primer plano» ${ }^{88}$. Con todo, la razón argumentativa de Balthasar es ya conocida, porque es el tema central de la teodramática: «Sólo cuando se las replantea en el horizonte de la liberación definitiva por Cristo y hacia Cristo es cuando el resto de los movimientos de liberación llegan a merecer su cualificación teológica» ${ }^{89}$.

\section{Conclusiones: la singularidad del ser}

A través de este trabajo se ha podido evidenciar cómo en la obra de Balthasar la cuestión del ser es el eje conductor del desarrollo de su planteamiento. Además, que es la paradoja natural del hombre, la que lo constituye como un ser dotado de sentido. Y en ella, cómo la libertad juega un rol preponderante en su accionar, ya que le permite descubrirse a sí mismo y, a la vez, debido a otro para ser pleno. El peligro es seguir el camino contrario: mal entender esta libertad originaria y pretender querer-ser-como-Dios, en su propia autorrealización personal y social, separando con ello el bien y el poder que le pertenecen al ser absoluto y que, el ser singular participando en él, sólo consigue rozar.

De ahí que se ha presentado como libertad, poder y mal se articulan en la medida que el ser singular concreto rechaza su paradoja natural. Introduciendo con ello mecanismos de control para someter y equilibrar este poder que ha quedado bajo su dominio, pero que forma parte de su estructura fundamental. Estableciendo un mundo cada vez más patético que mira su propia realización al interior de sí y que no es capaz de trascender hacia lo más pleno, sino por el contrario, quedando en la oscuridad propia del pecado y del mal.

Balthasar establece la circularidad de la paradoja: al reconocerla en el ser singular concreto que se orienta-a, y al reconocerla en el ser absoluto que se autocomunica y autorevela, como manifestación del ser que se da, en su propia autoconciencia. Cristo es el garante de esta circularidad. En él toma pleno sentido la pregunta por el sentido del ser, en aquel ser singular concreto que interroga sobre sí mismo y que se reconoce debido-a, y en aquel ser absoluto que se da a sí mismo como don para ser aprehendido como el bien y la verdad. Es por ello que Balthasar nos invita a observar la realidad de manera cristológica, de lo contrario,

\footnotetext{
88 TD 4, 458.

89 TD 4, 459.
} 
queda sumida en un ámbito intramundano que no consigue trascender y, por ende, llegar a su plenitud. Este es el motivo de la advertencia que nos hace de ciertos postulados teológicos, que incluso están presentes en la Constitución conciliar Gaudium et Spes y en la Teología de la Liberación.

A su vez, atendiendo a nuestra pregunta metódica, se puede afirmar con Balthasar que la singularidad del ser se vuelve positiva en la medida en que se constituye don en el Espíritu Santo. «En efecto, el tú que aquí afecta al hombre, no es un Alguien a quien se le añade la peculiaridad de amar, sino que es el Alguien que está constituido, en cuanto tal, por el amor mismo. El proceso trinitario-personal es 'el Amor'. $\mathrm{Y}$ esto no como un valor abstracto, ni tampoco como un valor colectivo, sino como algo personal y superior a toda comprensión. El Dios único (el Padre) me envía a mí (a nosotros) a su 'Hijo único', para llenarme a mí (a nosotros) internamente con su santo Espíritu de amor. Frente a este acontecimiento, la persona creada no encuentra en sí misma, en su estado propio, ninguna respuesta auténtica (...) su respuesta sólo puede ser dejar a Dios ser Dios en ella» ${ }^{90}$.

Ahora bien, la razón de este acontecimiento constituyente como don por parte del Espíritu Santo en el hombre la expresa el mismo Balthasar: «Este Espíritu, amor de Dios derramado en el corazón de los creyentes, realiza ambas cosas a la vez: liberar a la libertad finita llevándola hasta la auténtica libertad plena, y esto precisamente introduciéndola en la participación de la libertad infinita»" ${ }^{91}$.

Esto significa que en la medida que nos abrimos al ser de Dios, que participamos de su propio ser, la propia singularidad del hombre que se presenta en su propio ser, para plenificarse y alcanzar su esplendor tiene que necesariamente volcarse positiva. De lo contrario, su propia singularidad lo hará alejarse de Dios. En este sentido, el ser singular concreto, para ser pleno, necesita de Dios. Balthasar ve claramente el sentido trinitario de la participación de Dios en el hombre. Sin embargo, en esta etapa de la historia es el Espíritu de Dios quien anima a los hombres a llegar a su plenitud ${ }^{92}$. En palabras del teólogo suizo, si bien es Cristo el actor principal del teodrama, «De él mismo el Espíritu ha dado desde siempre testimonio de ser el Hijo único e incomparable del Padre. Pero dado que el Hijo a partir de su resurrección abre el espacio para el

90 H. U. vOn BaLthasaR: "El camino de acceso a la realidad de Dios", en Mysterium Salutis, II. Cristiandad, Madrid, 1969, 47. Cita tomada de San Juan de la Cruz: Llama III, 78.

\section{TD 2, 212.}

92 Balthasar desarrolla los distintivos del Espíritu Santo, a saber: don, libertad y testimonio. Que junto con pertenecer a cada una de las personas de la Trinidad, en él se ven de manera más nítida. Cfr. TL 3, 223ss. 
teodrama, puede conferir el Espíritu a los participantes en la trama hasta tal grado que ellos mismos pueden de modo análogo ser identificados como únicos»» ${ }^{93}$.

Desde otra perspectiva, Balthasar nos indica que «Es de nuevo a través del misterio del Espíritu Santo como se nos regalan a la vez dos cosas: un proyecto concreto de futuro que corresponde a nuestra misión más peculiar y con ello a nuestra persona, y la libre e íntima espontaneidad para cumplir, recordar y seguir este proyecto»» ${ }^{94}$.

Por tanto, frente al develamiento y ocultamiento del ser, que todo lo tiene y que sin embargo nada posee, la conciencia del ser singular concreto sólo podrá capturar su imagen, su bondad, en la medida en que el propio ser desee revelarse y ella desee aprehenderlo, para lograr trascender su propia finitud. En este sentido, es que se revela la participación del Espíritu Santo en el drama: «Donde el Espíritu arroja su luz, está con ello a la vez la diferencia y la identidad entre Padre e Hijo; la unidad de diferencia e identidad será vista simultáneamente, pero no comprendida; de esa manera, mediante la interpretación del Espíritu, en el encarnado se manifiesta a la vez algo comprensible y algo incomprensible» ${ }^{95}$.

En otras palabras: «En el despojamiento del ser como don del amor se revela el necesario sentido del ser. En él se legitima dicho sentido, por cuanto es el éter del despojamiento, su elemento vital y el poder que lo alienta (...) Precisamente porque la bonitas precede a todo despojamiento y no se despoja, mantiene, tanto el despojamiento del Padre como el del Hijo ${ }^{96}$. El bonum del Espíritu Santo no solo presupone la doble autoentrega (exinatio) de Padre e Hijo, sino que la incluye en sí» ${ }^{97}$.

Esto quiere expresar para Balthasar que «El Espíritu como fruto del amor -que renuncia al propio ser- no se despoja, precede a todo despojamiento y sostiene el despojamiento del Padre y del Hijo, de quienes a la vez es fruto. De ahí que, en cuanto don absoluto da testimonio del amor del Hijo, quien no posee más que todo el amor del Padre. Por tanto, es la gratuidad vivida del amor intratrinitario. Con ello queda manifestado el carácter de donum del Espíritu Santo, en cuanto bonum» ${ }^{98}$.

Con todo, es posible afirmar que la singularidad del ser se vuelve positiva en el Espíritu Santo; por una parte, en la medida que es la fuerza

\footnotetext{
93 TD 3, 56.

94 TD $3,57$.

95 TL 3, 31.

96 TL 3, 228.

97 TL 3, 235.

98 TL 3, 237.
} 
común que poseemos los cristianos visiblemente y que nos hace partícipes en la libertad de Cristo que nos lleva al Padre; y por otra, en la medida que actúa como fuerza invisible que habita en cada uno de los hombres que buscan el bien y la verdad. En ambos casos, es el auxilio divino (paráclito) que ha dejado Cristo en su Iglesia y en el mundo que puede ayudar a superar la actual paradoja de la existencia humana, tanto a nivel personal como social, al interrogar sobre la cuestión del ser, porque el mismo Espíritu nos abre hacia el verdadero ser que nos trasciende, al ayudarnos a reconocer nuestra finitud y al desear participar de la infinitud de Dios, mediante su propia donación de amor.

Sumario: Introducción; 1. Aproximación al pensamiento del autor; 2. La paradoja natural del hombre; 3. Rechazo de la paradoja natural; 4. El problema del mal; 5. La actual situación del mundo (una crítica a la Gaudium et spes y a la Teología de la liberación); 6. Conclusiones: la singularidad del ser. 